\title{
The Role of Cathelicidin LL-37 in Cancer Development
}

\author{
Ewelina Piktel $^{1} \cdot$ Katarzyna Niemirowicz $^{1} \cdot$ Urszula Wnorowska $^{1} \cdot$ \\ Marzena Wątek ${ }^{2} \cdot$ Tomasz Wollny $^{2} \cdot$ Katarzyna Głuszek $^{2} \cdot$ Stanisław Góźdź $^{3}$. \\ Ilya Levental ${ }^{4} \cdot$ Robert Bucki $^{1,5}$
}

Received: 1 April 2015/Accepted: 29 May 2015/Published online: 22 September 2015

(c) The Author(s) 2015. This article is published with open access at Springerlink.com

\begin{abstract}
LL-37 is a C-terminal peptide proteolytically released from $18 \mathrm{kDa}$ human cathelicidin protein (hCAP18). Chronic infections, inflammation, tissue injury and tissue regeneration are all linked with neoplastic growth, and involve LL-37 antibacterial and immunomodulatory functions. Such a link points to the possible involvement of LL-37 peptide in carcinogenesis. An increasing amount of evidence suggests that LL-37 can have two different and contradictory effects-promotion or inhibition of tumor growth. The mechanisms are tissuespecific, complex, and depend mostly on the ability of LL37 to act as a ligand for different membrane receptors whose expression varies on different cancer cells. Overexpression of LL-37 was found to promote development and progression of ovarian, lung and breast cancers, and to suppress tumorigenesis in colon and gastric cancer. This review explores and summarizes the current views on how LL-37 contributes to immunity, pathophysiology and cell signaling involved in malignant tumor growth.
\end{abstract}

Robert Bucki

buckirobert@gmail.com

1 Department of Microbiological and Nanobiomedical Engineering, Medical University of Białystok, Mickiewicza 2c, 15-222 Białystok, Poland

2 Holy Cross Oncology Center of Kielce, Kielce, Poland

3 The Faculty of Health Sciences of The Jan Kochanowski University in Kielce, Kielce, Poland

4 Department of Integrative Biology and Pharmacology, The University of Texas Medical School, Houston, TX, USA

5 Department of Physiology, Pathophysiology and Microbiology of Infections, Faculty of Health Sciences of The Jan Kochanowski University in Kielce, Kielce, Poland
Keywords Cancer - Immune system - Carcinogenesis · Cathelicidin $\cdot$ LL-37

\section{Introduction}

Effective cancer treatment is one of the major challenges for modern medicine. It has been proven that the majority of these cases are strongly associated with the western lifestyle and only $5-10 \%$ of the malignancies are genetically conditioned (Anand et al. 2008). Although present knowledge about risk factors increasing the possibility of cancer development is satisfactory, data of the mechanisms that directly cause malignant transformation are still insufficient. For this reason, increasing knowledge of the mechanisms governing the biology of the tumor should be a priority. We believe that particularly important issue should be searching of new links between cancer and the human immune system. Such a link represents a family of proteins named cathelicidins. They are essential components of innate immunity-together with defensins and other antimicrobial peptides (AMPs) they provide a first line of defense against a variety of pathogens. About 30 cathelicidin family members have been described in mammals, however, in humans only one, hCAP-18, has been identified. hCAP-18 is mostly expressed by neutrophils, monocytes, mast and dendritic cells (Agerberth et al. 2000; Vandamme et al. 2012), although its expression can also be induced during infection in epithelial cells and human keratinocytes (Bals et al. 1998; Frohm et al. 1997). hCAP-18 is a precursor for the AMP LL-37, which is released by proteinase 3-mediated extracellular cleavage (Scott et al. 2002; Sørensen et al. 2001). Many studies have revealed that hCAP-18 and LL-37 possess a wide range of pleiotropic properties (Bucki et al. 2010) including 
antimicrobial activities against bacteria, viruses, fungi and parasites (Bals et al. 1998; Barlow et al. 2011; Bucki et al. 2004; Bucki and Janmey 2006; Currie et al. 2013; Leszczynska et al. 2013; López-García et al. 2005; RicoMata et al. 2013; Wang 2014; Zaiou and Gallo 2002). At low concentrations, LL-37 inhibits the formation of bacterial biofilms, even in the case of microorganisms resistant to conventional antibiotics (Dosler and Karaaslan 2014; Overhage et al. 2008). However, the antimicrobial properties of LL-37 are reduced in patients with cystic fibrosis as a result of the interaction of the peptide with the DNA, F-actin and mucins (Bucki et al. 2007) or are inactivated by protease (Sieprawska-Lupa et al. 2004). In contrast to that, synthetic derivatives of AMPs are characterized by resistance to inactivation by polyelectrolytes (Bucki et al. 2007, 2008) and to protease digestion (Kuroda et al. 2013).

The spectrum of LL-37 activity includes also activation of cell proliferation, epithelial cells migration, and promotion of wound closure, which together play an important role in tissue homeostasis and regenerative processes (Shaykhiev et al. 2005). A summary of the pleiotropic properties of the LL-37 peptide is presented in Fig. 1. Aside from its effect on individual cells, LL-37 may play an important role in governing the function of mucosal barriers, which implicates its more complex regulatory effect at tissues level. LL-37 treatment increases the stiffness and decreased the transepithelial permeability of confluent monolayer of lung epithelial cells, which correlated with decreased bacterial translocation into the cells
(Byfield et al. 2011). Such effects are believed to prevent chronic infection of the mucosal barrier by pathogenic bacteria such as Pseudomonas aeruginosa. These pleiotropic activities of the LL-37 peptide likely occur due to its agonistic effect on various membrane receptors. The chemotactic properties of LL-37 involve its interaction with formyl peptide receptor like-1 (FPRL-1) (De Yang et al. 2000). Activation of FPRL-1 by LL-37 has been implicated in immune surveillance against neoplastic transformation, wherein cells of the immune system such as natural killer lymphocytes (NKs) and type $1 \mathrm{CD}^{+} \mathrm{T}$ lymphocytes recognize and destroy cancer cells (OstrandRosenberg 2008). Such tumor-suppressing activity of formyl peptide receptor family after activation with LL-37 peptide was also recently reported for gastric cancer (Prevete et al. 2015). Conversely, the interaction of LL-37 with FPRL-1 has also been implicated in the metastatic progression of ovarian cancer cells, via FPRL-1-mediated recruitment of mesenchymal stromal cells (MSCs) (Coffelt et al. 2009).

The biological actions of LL-37 peptide are also mediated by the activation of purinergic receptor $\mathrm{P} 2 \mathrm{X} 7$ and epidermal growth factor receptor (EGFR) (von Haussen et al. 2008). Activation of $P 2 X 7$ leads directly to increased secretion of proinflammatory cytokines interleukin (IL)- $1 \beta$ and IL-8 (Ferrari et al. 2006; Montreekachon et al. 2011), polymorphisms of which have recently been implicated in some types of malignancies (Gao et al. 2014; Koensgen et al. 2015). LL-37 acts as a physiological
Fig. 1 The pleiotropic properties of LL-37 in relation to the different cells and tissues. MSCs: mesenchymal stromal cells

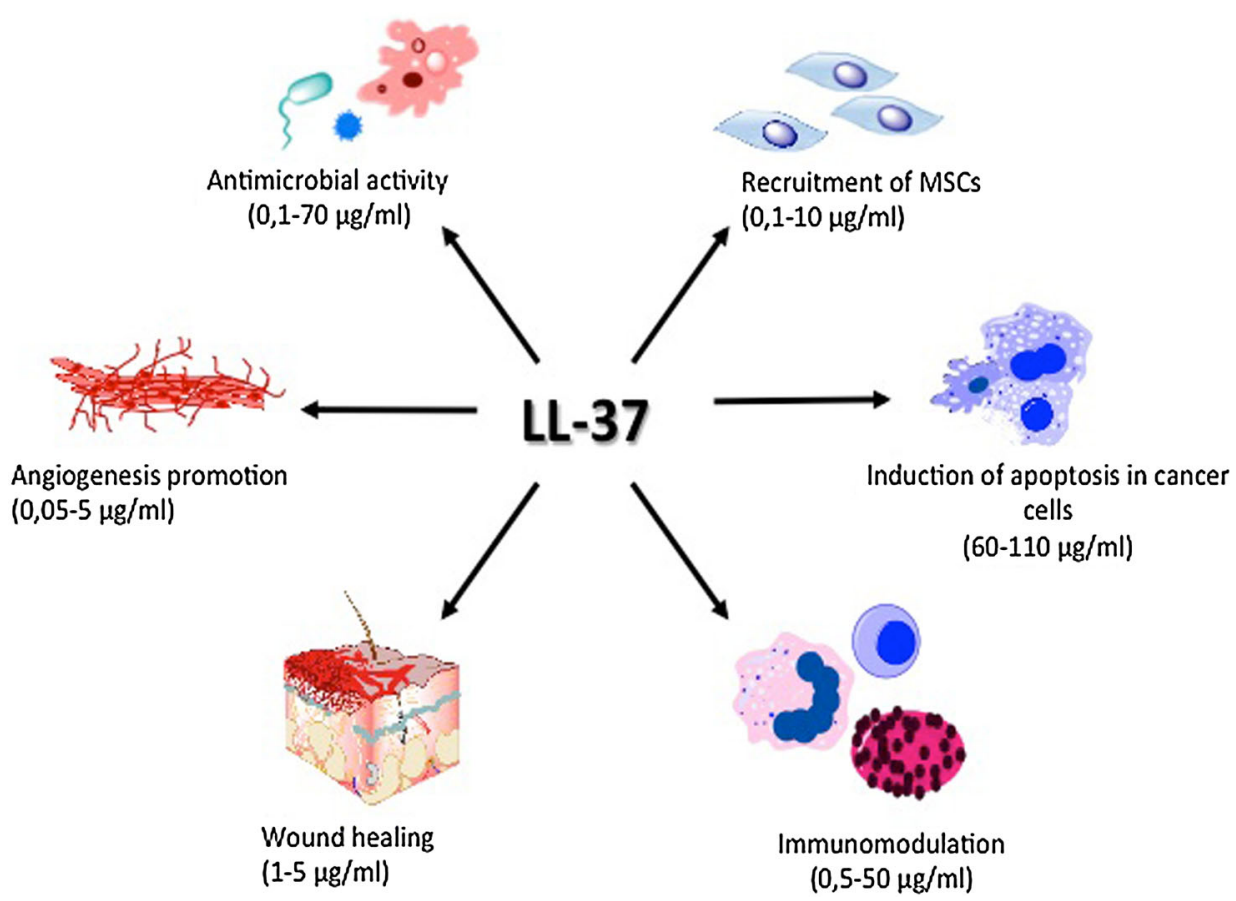


immunomodulator that might control the inflammation at infection/injury sites and influences the process of cell regeneration. Furthermore, LL-37 is able to activate insulin-like growth factor-1 receptor (IGF-1R), which results in increased cell proliferation and expression of metastatic phenotype (Girnita et al. 2012).

In addition to its functions in human immunity, cathelicidin plays a role as an inducer of angiogenesis (Koczulla et al. 2003). This notion is supported by an important link between LL-37 and regulation of apoptosis. It is generally accepted that a loss of balance between cell proliferation and cell death is essential in tumor development (Ouyang et al. 2012) and regulation of apoptosis by LL-37 might be involved in pathogenesis of malignant tumors.

LL-37-induced apoptosis explains its antitumor activity in colon cancers and hematologic malignancies (Mader et al. 2009; Ren et al. 2012, 2013). However, LL-37 can also promote tumor growth, depending on the tissue from which the cancer cells originate. Indeed, in various types of cancer a different expression of LL-37 peptide was observed. In ovarian, lung, breast cancer and malignant melanoma cells increase expression was reported (Bals et al. 1998; Coffelt et al. 2008; Heilborn et al. 2005; Kim et al. 2010). In contrast, cells from colon or gastric cancers produce lower amounts of this peptide (Hase et al. 2003; Ren et al. 2012). These observations imply that the actions of LL-37 are tissue-specific (Table 1). In this review, we summarize the role of LL-37 in the development of the most common types of cancer. We emphasize that in many of these, the mechanisms by which LL-37 exerts its protumorigenic or anti-cancer effect have not been fully understood.

\section{Ovarian Cancer}

Each year, over 200,000 women are diagnosed with ovarian cancer, and although up to $44 \%$ of women survive 5 years after diagnosis, ovarian cancer is the leading cause of death among all gynecological malignances (Muccioli and Benencia 2014; Romero and Bast 2012). A number of studies have shown that proinflammatory factors are involved in ovarian cancer development (Clendenen et al. 2011; Macciò and Madeddu 2012). In particular, tumor necrosis factor (TNF)- $\alpha$, IL- $1 \beta$ and IL- 6 are associated with ovarian tumorigenesis (Clendenen et al. 2011). Additionally, the correlation between increasing C-reactive protein level and risk of ovarian cancer development was described (Clendenen et al. 2011; McSorley et al. 2007). Recent reports have demonstrated increased secretion of LL-37 in ovarian tumors compared to normal ovary cells, implicating the role of LL-37 in ovarian cancer development (Fig. 2) (Coffelt et al. 2008). Based on these results we suggest that measurement of hCAP-18/LL-37 blood level might be proposed as a potential biomarker for ovarian cancer. Interestingly, the increase in concentration of the LL-37 peptide was observed in early stage, i.e. grade I ovarian tumors (Lim et al. 2013). Considering that a significant mortality from ovarian cancer is largely due to late detection, the identification of for ovarian cancer early markers could significantly increase the survival of women affected by this disease.

\section{Tumorigenic Effect of LL-37 in Ovarian Cancer Tissues Via MSC Recruitment}

Several studies indicate that overexpression of LL-37 peptide in ovarian epithelial cells acts as a positive regulator of ovarian cancer progression. LL-37 promotes tumorigenesis through its ability to endorse engraftment of bone marrow-derived, multipotent mesenchymal stromal/ stem cells (MSCs) into the tumor stroma, where they contribute to tumor progression and metastasis (Coffelt et al. 2009; Wu et al. 2010c). MSCs also carry a high capacity for the production of a variety of cytokines and growth factors, ultimately inducing immunomodulatory effects on various cells associated with carcinogenesis (Chen et al. 2011; Coffelt et al. 2009; Wu et al. 2010c). LL37 augments the pro-tumorigenic nature of MSCs by recruiting them to ovarian tumors through FPRL-1 (Coffelt et al. 2009). Neutralization of LL-37 in vivo, using an antiLL-37 antibody, significantly reduced the engraftment of MSCs into ovarian tumor xenografts developed from OVCAR-3 ovarian cancer cells, resulting in inhibition of tumor growth as well as disruption of the fibrovascular network (Coffelt et al. 2009).

In addition to LL-37, several cytokines, including IL6, stromal cell-derived factor 1 and prostaglandin E2 (PGE2) were implicated in MSCs recruitment, thus neutralization of LL-37 did not completely block MCSs migration (Coffelt et al. 2009; Touboul et al. 2014). However, LL-37 resulted in a significant number of vascular channels in nude mice. These data indicate that LL-37-mediated recruitment of MSCs can also facilitate ovarian tumor progression through secretion of pro-angiogenic factors. Thus, a significant contributor to the role of LL-37 in ovarian cancer development is its enhancement of MSCs secretion of IL-1 $\beta$, IL-6, IL-8, IL10 and TNF- $\alpha$ (and reduction of IL-12 expression). Consistently, in vitro endothelial cell formation by MSCs is enhanced with LL-37 presence with positive effect on tumor growth (Touboul et al. 2014). Finally, MSCs are associated with enhanced tumor aggressiveness by their immunosuppressive effects on NKs or $\mathrm{T}$ cells, which reduce the body's response to the growing tumor (Chen et al. 2011). 
Fig. 2 Dual role of LL-37 in ovarian cancer development. LL-37: cathelicidin LL-37, $C p G-O D N: \mathrm{CpG}$ oligodeoxynucleotides, $T N F-\alpha$ : tumor necrosis factor $\alpha, I F N-\gamma$ : interferon $\gamma, I L$ : interleukin

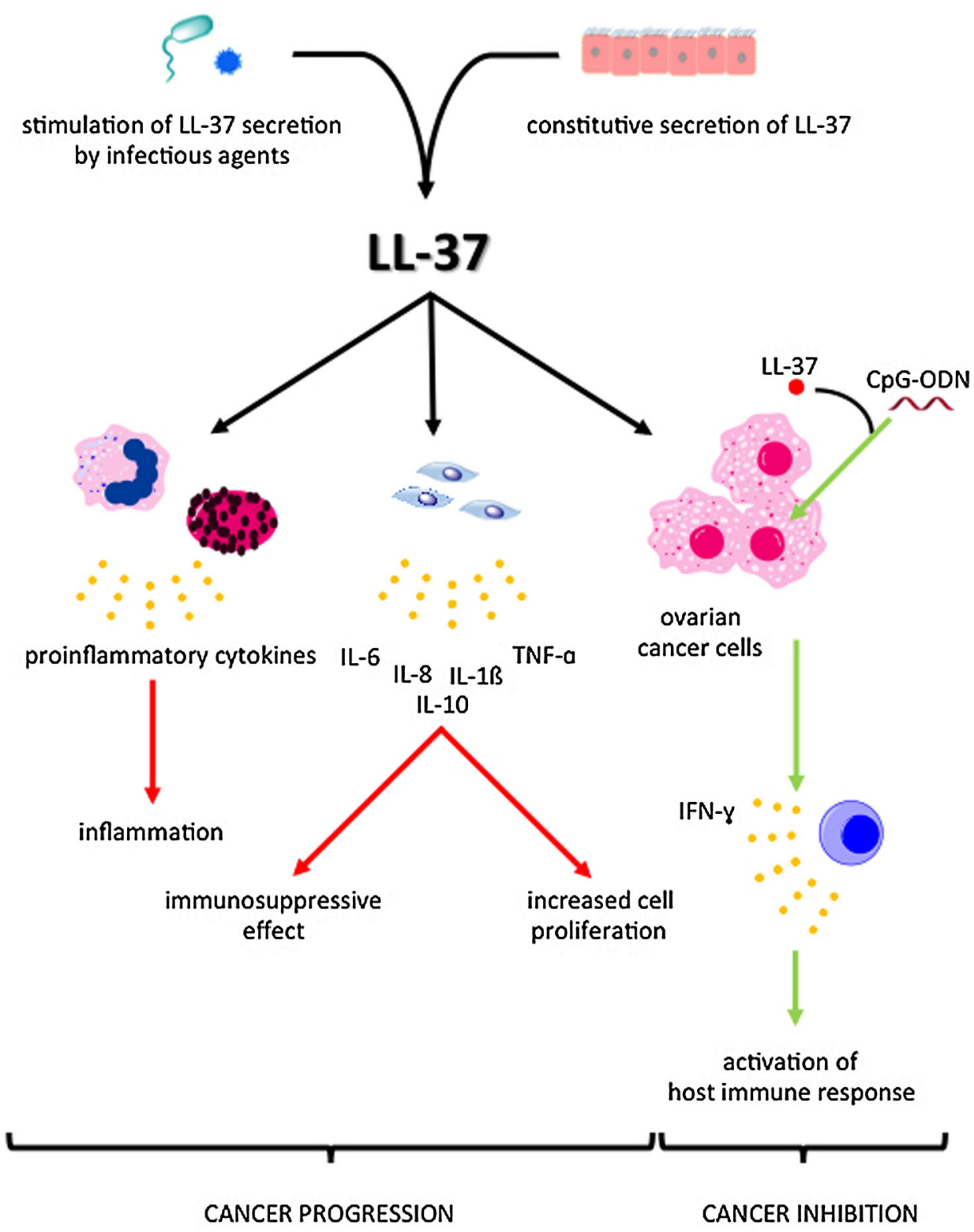

\section{LL-37 Enhances Chemotherapeutic Effects of CpG Oligodeoxynucleotides}

Opposing the angiogenic and inflammatory activities of LL-37-mediated recruitment of MSCs, LL-37 has shown synergistic toxicity against ovarian cancer cells in combination with other Toll-like receptor (TLR) ligands such as CpG-ODN (Chuang et al. 2009; Hurtado and Peh 2010). Co-administration of LL-37 and CpG-ODN increases the delivery of CpG-ODN into the endosomal compartments, where it can bind to TLR9 and activate the immune system. This effect might result from the membrane activity of LL37 , as its insertion into the plasma membrane may affect membrane fluidity and bilayer membrane architecture. The combined CpG-ODN/LL-37 therapy, expression of interferon (IFN)- $\gamma$, inducing proliferation and activation of natural killer (NK) cells, but not $\mathrm{CD} 4^{+}$or $\mathrm{CD} 8^{+} \mathrm{T}$ cells, in the peritoneal cavity, ultimately increase the organism's natural defenses against the cancer cells (Chuang et al. 2009).

\section{Lung Cancer}

The presence of hCAP-18/LL-37 in epithelial cells of human lungs as well as in mucous cells of the submucosal glands is well studied (Agerberth et al. 2000; Scott et al. 2002; Vandamme et al. 2012). Additionally, LL-37 is secreted into the airway surface fluid, where it serves its most recognized function of defending the conducting 
airway against pathogenic microorganisms, via its antimicrobial activity against a large spectrum of respiratory pathogens, including respiratory syncytial virus, influenza viruses, P. aeruginosa, and Staphylococcus aureus (Bals et al. 1998; Barlow et al. 2011; Currie et al. 2013; Dosler and Karaaslan 2014; Travis et al. 2000; Wang 2014). LL37 also facilitates the regeneration of damaged lung epithelial tissues (Shaykhiev et al. 2005). However, a loss of control of this mitogenic activity might be associated with lung cancer.

\section{LL-37 is Up-Regulated and Acts as Growth Factor in Lung Cancer}

Conducted studies revealed that lung cancer cells express hCAP-18/LL-37 at higher levels. In a large percentage of patients diagnosed with squamous cell cancer and adenocarcinoma, increased levels of cathelicidin were also observed in serum. The same effect was confirmed in both in vivo and in vitro models. Those studies revealed that human cathelicidin stimulates proliferation of bronchial cancer cells and established a positive correlation between the progression of lung cancer and the blood level of LL-37 (von Haussen et al. 2008).

The pro-tumorigenic mechanism of LL-37 appears to involve the activation of EGFR (von Haussen et al. 2008), a tyrosine kinase receptor widely implicated in lung cancer development. Addition of the LL-37 peptide at low concentrations $(5 \mathrm{ng} / \mathrm{ml})$ to lung cancer cell lines induced phosphorylation of the EGFR and activation of downstream MAP kinase signaling pathways, leading to enhanced proliferation and growth of anchorage-independent colonies. Lung cancer cell lines stably overexpressing the LL-37 peptide by means of a doxycycline-regulated promoter system also showed faster growth. The mechanism behind these observations may be related to LL-37mediated activation of a metalloproteinase that cleaves membrane-anchored EGFR ligands (Tjabringa et al. 2003; von Haussen et al. 2008).

\section{Potential Role of LL-37 in Lung Cancer Development is Link to IL-32 Expression}

IL-32, previously known as NK-4, is one of the recently described proinflammatory cytokines produced by immune cells (monocytes, $\mathrm{T}$ lymphocytes) and non-immune epithelial and endothelial cells. IL-32 induces the production of several other cytokines and chemokines, including TNF- $\alpha$, IL-1 $\beta$, IL-6, IL-8 or IL-18, and activates the NF$\kappa \mathrm{B}$ and p38 MAP kinase pathways (Dinarello and Kim 2006; Felaco et al. 2009; Yousif et al. 2013). These properties, coupled with pro-angiogenic attributes (Nold-Petry et al. 2014) of IL-32, make it an interesting candidate in cancer development. Expression of IL-32, produced during autoimmune disease development including inflammatory bowel disease was found to increase in cervical cancer (Joosten et al. 2006; Lee et al. 2011; Shioya et al. 2007). Expression of IL-32 also rises during Mycobacterium tuberculosis infection, and caspase-1/IL-18/IFN- $\gamma$ pathway governs its production (Netea et al. 2006). Given that $M$. tuberculosis infections are risk factors associated with development of lung cancer, IL-32 was suggested as a possible link between chronic lung infection and lung cancer development (Simonsen et al. 2014). Indeed, recent studies indicate that the expression of IL-32 is significantly altered in lung cancer cells compared to normal cells. It occurs in advanced cancer and exhibits a histology-specific type pattern (Sorrentino and Di Carlo 2009). Expression of IL-32 is also associated with increased lung cancer invasiveness, metastatic ability and poor prognosis (Zeng et al. 2014). In all lung cancer histotypes stromal leukocytes may also account for a considerable expression of IL-32, inside both, IL-32 positive and IL-32 negative tumors. IL-32 expressing leukocytes were identified as $\mathrm{CD}^{+} 8^{+}$macrophages and $\mathrm{CD} 3^{+} \mathrm{T}$ cells, mainly of $\mathrm{CD} 4^{+}$phenotype, both of which are well-known IL-32 producers. IL-32 ability to activate gene transcription factor- $\mathrm{NF}-\mathrm{\kappa B}$, was propose to promote lung cancer progression. LL-37 and its shorter derivative IG-19 significantly suppress IL-32-induced production of pro-inflammatory cytokines such as TNF- $\alpha$ and IL-1 $\beta$. In contrast, LL-37 and IG-19 enhance the production of the anti-inflammatory cytokine IL-1RA. LL37 and IG-19 suppress IL-32-mediated phosphorylation of Fyn (Y420) Src kinase. However, IL-32-mediated phosphorylation of AKT-1 and MKP-1 was not suppressed. LL37 and IG-19 alone induce the phosphorylation of MKP-1, which is a known negative regulator of inflammation. Furthermore, the peptides induce the activity of p44/42 mitogen-activated protein kinase (MAPK), which is known to phosphorylate MKP-1. Taking into the account previous studies showing an antagonistic activity of LL-37 against IL-32 in gastric cancer cells (Choi et al. 2014), it might be assumed that similar relationship function during lung cancer development.

\section{Breast Cancer}

LL-37 is an important factor of the innate human defense system of the mammary gland epithelium in human breast (Armogida et al. 2004). However, increased expression of LL-37 was also observed in breast cancer cells, with secreted concentrations correlating to phenotypic tumor severity (Heilborn et al. 2005). Evaluation of hCAP18/LL37 ability to promote breast cancer development revealed that metastatic potential greatly increases as a result of 
augmented Heregulin-mediated mitogenic signaling through ErbB2. A modified version of LL-37 competitively inhibited LL-37 induced MAPK phosphorylation and drastically reduced cancer cell colonies induced by LL-37, in addition to inhibiting cancer cell migration (Weber et al. 2009).

\section{Colon Cancer}

Early diagnosis of colon cancer is crucial for therapeutic success, since mortality is high in the late stages of disease-median length of survival is 5-6 months (Van Cutsem and Geboes 2007). In 2012, over 100,000 new cases were diagnosed in the United States alone (Mishra et al. 2013). In most colon cancer cells, a complete loss of hCAP18/LL-37 expression was noted (Ren et al. 2012). Therefore, low levels of LL-37 expression might serve as a biomarker of colon cancer (Lim et al. 2013; Ren et al. 2012).

\section{LL-37 and Its Derivatives FK-16 and FF/CAP-18 Suppress Colorectal Cancer Cells Growth}

Decreased secretion of LL-37 peptide in colorectal cancer facilitates cancer growth. Interestingly, LL-37 and its fragments, FK-16 (16-residue peptide derived from residues 17-32 of LL-37-discovered and demonstrated to have anti-cancer activity by Li et al. (2006)) and FF/CAP18 (designed by replacement of glutamic acid and lysine residue with phenylalanine) display anti-proliferative effect against colon cancer cells (Kuroda et al. 2012; Ren et al. 2012, 2013). Pro-apoptotic activity of LL-37 and its derivatives may be enhanced using magnetic nanoparticles (MNPs) as drug delivery systems (Fig. 3). Recent studies revealed, that immobilization of LL-37 on the surface of MNPs significantly increases antitumor activity of LL-37 against colon cancer DLD-1 and HT-29 cell lines (Niemirowicz et al. 2015).

LL-37 appears to interfere with colon cancer development by affecting the epithelial-mesenchymal transition and tumor-associated fibroblasts. The mechanism of this effect is related to the cytoskeletal architecture of fibroblasts, which is related to their ability to support division of colon cancer cells. Importantly, animal models suggested that the cathelicidin protein family directly prevented colon cancer growth, as administration of mouse cathelicidin peptide by enema to the area of colon cancer growth significantly reduced the number and area of colonic tumors. Additionally, at the cytoskeletal level, it was observed that cathelicidin preferentially affected tumoral vimentin, but not mouse host fibroblast vimentin. In view of the fact that vimentin production in tumor stroma is linked with short survival time of patients suffering from colon cancer, targeted treatment with cathelicidin appears to be a promising direction (Cheng et al. 2014).

\section{LL-37 and FK-16 Activate Caspase-Independent Apoptosis in Colon Cancer Cells}

In some cancer cells, stimulation of colon cancer cells by LL-37-and its derivative peptides-induces hallmarks of apoptosis, including phosphatidylserine externalization and DNA fragmentation, without activation of caspases (Ren et al. 2012). Induction of apoptosis in caspase-independent manner was verified by analyzing the cleavage of Poly (ADP-ribose) polymerase (Galluzzi et al. 2008). Not only was caspase activity not increased, but even a decrease in the activity of these enzymes was noted, strengthening the hypothesis of caspase-independent mechanism of LL-37 action (Ren et al. 2012). Initiation of apoptosis without activation of caspases is an important observation, considering the latest data indicating the impact of caspasedependent apoptosis for repopulation of cancer cells (Donato et al. 2014; Huang et al. 2011). Recent studies suggest that activated caspase- 3 positively regulates cancer cell proliferation and stimulates tumor growth via increased activation of PGE2-one of the factors that can strongly stimulate growth of surviving cancer cells.

Caspase-independent apoptosis of colon cancer cells is mediated by apoptosis inducing factor (AIF) and endonuclease $\mathrm{G}$ (EndoG), involved in DNA degradation. For this activity, the proteins must be translocated from mitochondria, where they normally localized, into the nucleus. LL-37 significantly increases the nuclear level of AIF and EndoG (Ren et al. 2012). Another requirement for caspaseindependent apoptosis of cancer cells is increased activity of Bcl-2 and p53 (Arnoult et al. 2003). The expectation that LL-37 would increase the production of pro-apoptotic Bax and Bak and reduce the level of antiapoptotic Bcl-2 was experimentally confirmed, in addition to the observation of the enhanced expression of PUMA, a direct target gene of p53 in HCT116 cells, after treatment with LL-37 (Ren et al. 2012). It was reported, that viability of colon cancer cells is also reduced in response to treatment with FK-16 (Ren et al. 2013). Here again, a caspase-independent mechanism was inferred, evidenced by DNA fragmentation and phoshatidylserine externalization via $G i$-coupled GPCRp53-Bcl-2/Bax/Bak-AIF/EndoG cascade. FK-16 actually possessed higher potency against colon cancer cells compared to LL-37, though the viability of LoVo and HCT116 cells was significant reduced by both peptides, suggesting both LL-37 and FK-16 as interesting possibilities for colorectal cancer treatment (Ren et al. 2013).

Finally, the biological activity of LL-37 analogue FF/ CAP18 and its influence on the viability of the colon cancer cells line HCT116 has been investigated as well. 
Fig. 3 Activation of autophagy and caspase-independent apoptosis pathway and proposed mechanism of action of magnetic nanoparticles functionalized with LL-37 on colon cancer cells. $L L-37$ : cathelicidin LL-37, GPCR: G-protein coupled receptor, p53: tumor protein p53, Bax: BCL2-assiociated X protein, Bak: Bcl-2 homologous antagonist, Atg5/7: autophagyrelated protein 5/7, EndoG: endonuclease G, $A I F$ : apoptosis inducing factor, $M N P$ : magnetic nanoparticles, ROS: reactive oxygen species

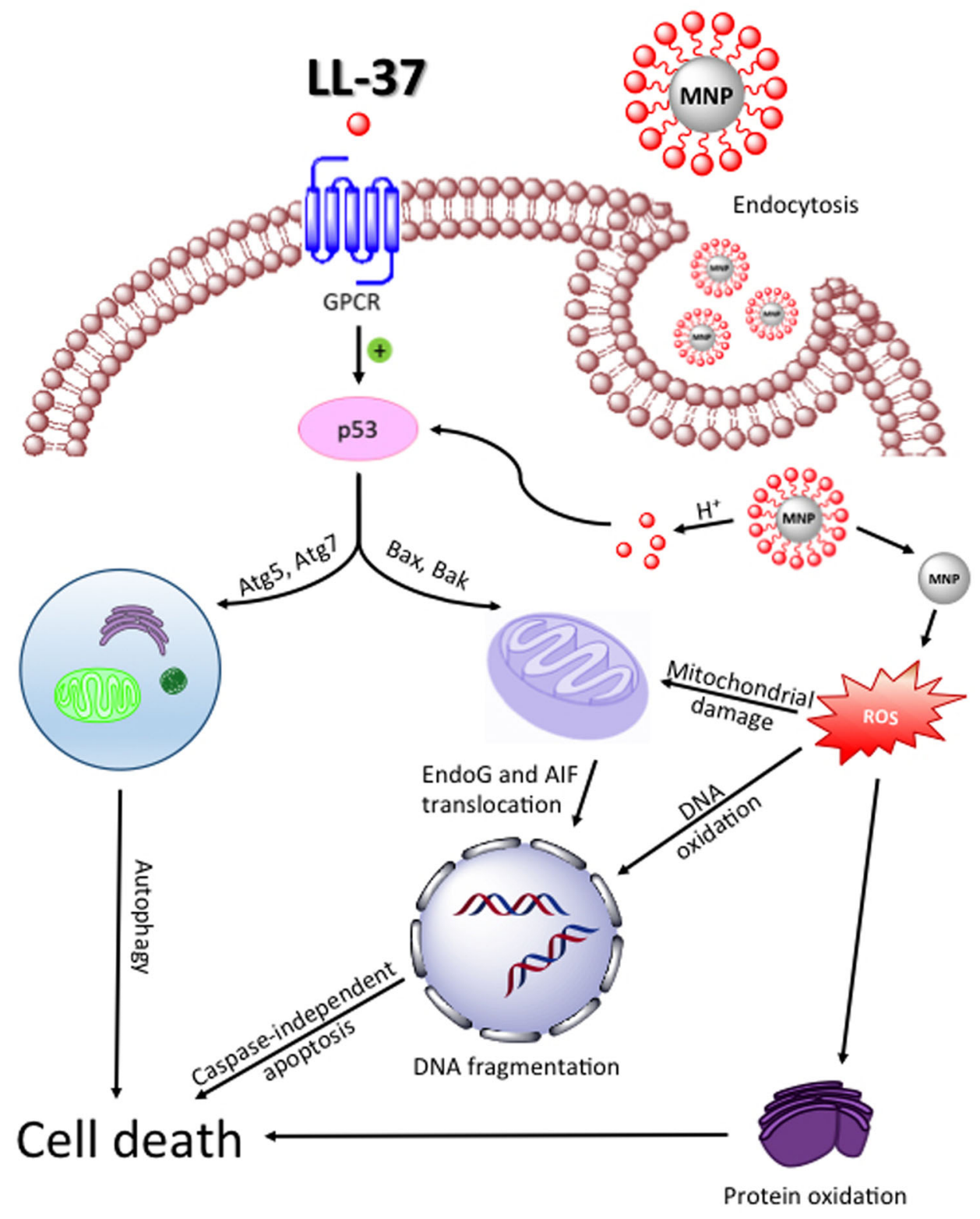

Interestingly, FF/CAP18 possesses greater growth inhibition capability, when it is compared to LL-37. Detailed analysis of the observed effect again supports the conclusion that decreased survival of cancer cells is mediated by the induction of the caspase-independent apoptotic pathway via the loss of mitochondrial membrane potential. The increased effectiveness of FF/CAP-18 in comparison with the LL-37 is likely attributable to the higher negative charge (Kuroda et al. 2012).

\section{FK-16 Initiates Cell Death Via Autophagy}

With respect to the mechanism of cell toxicity of LL-37 derivatives, one of the key findings was the observation of
FK-16-initiated autophagic cell death (autophagocytosis) via increased expression of autophage-related proteins LC3-I, LC3-II, Atg5, and Atg7 (Ren et al. 2013). Autophagy may play a dual role in cancer development, either inhibiting or promoting tumor growth (Wu et al. 2012). For example, the key tumor suppressor protein p53 positively regulates autophagy in cancer cells (Levine and Abrams 2008; Zeng et al. 2007). The study showed that the FK-16 fragment induces cell death by both caspase-independent apoptosis and autophagy. Particularly interesting is the observation linking both these processes. It was found that the abolition of autophagy results in increasing cell death via apoptosis and vice versa. This dual, mutually dependent mechanism of inducing cell death is essential for anti- 
Table 1 The mechanism of pro-tumorigenic and anti-cancer activity of LL-37 and alternation of its expression in various types of cancer

\begin{tabular}{|c|c|c|c|}
\hline Type of cancer & $\begin{array}{l}\text { Change in } \\
\text { expression } \\
\text { of LL-37 }\end{array}$ & $\begin{array}{l}\text { Mechanism of pro-tumorigenic/anti-cancer } \\
\text { activity of LL-37 in cancer cells }\end{array}$ & References \\
\hline Ovarian cancer & $\uparrow$ & $\begin{array}{l}\text { Recruitment of MSCs and increasing of their invasiveness } \\
\text { and immunosuppressing effect via FPRL-1 } \\
\text { Enhancing chemoresistance of cancer cells } \\
\text { Increasing of therapeutic effect of CpG-ODN (augmented } \\
\text { delivery of CpG-ODN into cancer cells), increasing of } \\
\text { proliferation and activation of immune cells }\end{array}$ & $\begin{array}{l}\text { Castells et al. (2013), Coffelt et al. } \\
\quad(2008,2009) \text {, Cohen et al. } \\
\quad(2013) \\
\text { Chuang et al. (2009) }\end{array}$ \\
\hline Colon cancer & $\downarrow$ & $\begin{array}{l}\text { Activation of cancer cell apoptosis in caspase-independent } \\
\text { manner via GPCR-p53-Bcl-2/Bax/Bak-AIF/EndoG } \\
\text { cascade } \\
\text { Promotion of cancer cells death via autophagy process }\end{array}$ & $\begin{array}{l}\text { Kuroda et al. (2012), Ren et al. } \\
\quad(2012,2013)\end{array}$ \\
\hline Gastric cancer & $\downarrow$ & $\begin{array}{l}\text { Control of the IL- } 32 \gamma \text {-induced inflammation by activation } \\
\text { of p } 44 / 42 \text { MAPK } \\
\text { Inhibition of proteasome in gastric cancer tissues and } \\
\text { activation of BMP/p } 52 \text { cascade } \\
\text { Inhibition of angiogenesis via FPR } 1 \text { activation }\end{array}$ & $\begin{array}{l}\text { Choi et al. (2014), Hase et al. } \\
\text { (2003), Prevete et al. (2015), } \\
\text { Wu et al. (2010b) }\end{array}$ \\
\hline Lung cancer & $\uparrow$ & Activation of EGFR and MEK/ERK1/2 signaling pathway & von Haussen et al. (2008) \\
\hline Breast cancer & $\uparrow$ & Stimulation of ERB-family receptors & Heilborn et al. (2005) \\
\hline Malignant melanoma & $\uparrow$ & Unstudied & Kim et al. (2010) \\
\hline Hematological malignancies & $\downarrow$ & Induction apoptosis of cells in caspase-independent manner & $\begin{array}{l}\text { An et al. (2005), Mader et al. } \\
\text { (2009) }\end{array}$ \\
\hline Prostate cancer & $\uparrow$ & $\begin{array}{l}\text { Initiation of phosphorylated Erk } 1 / 2 \text { and Akt signaling } \\
\text { pathway }\end{array}$ & Hensel et al. (2011) \\
\hline Open-ended & & $\begin{array}{l}\text { Inhibition of telomerase enzyme via binding telomeric } \\
\text { G-quadruplex }\end{array}$ & Neidle (2010) \\
\hline Open-ended & & $\begin{array}{l}\beta \text {-Arrestin-1-dependent activation of MAPK/ERK } \\
\text { signaling pathway via activation of IGR-1R }\end{array}$ & Girnita et al. (2012) \\
\hline
\end{tabular}

cancer activity of FK-16 (Ren et al. 2013). The activation of p53 in colon cancer cells observed under LL-37 or FK16 treatment underline the potential of this pathway as a new approach towards colon cancer therapy.

\section{Gastric Cancer}

Many factors are involved in development of gastric cancer. Among them, Helicobacter pylori plays a key role in stomach carcinogenesis, as evidenced by epidemiological and clinical studies (Kim et al. 2014; Wu et al. 2010b). However, the newest survival analysis conducted in 2014 revealed that $H$. pylori infection as a prognostic factor for gastric cancer patient is not clear (Kim et al. 2014). There is an intimate relationship between cancer and inflammation, and $H$. pylori infection induces inflammation and intensifies secretion of pro-inflammatory cytokines. Inflammation associated with chronic gastritis was linked with neoplastic formation (Alzahrani et al. 2014). The fact that hCAP-18/LL-37 is also released during inflammatory processes suggests a possible link between these peptides and gastric cancer.

\section{LL-37 is Up-Regulated during H. pylori Infection, but is Down-Regulated in Gastric Cancer Tissues}

Based on the research carried out by Choi et al. (2014) it was established that LL-37 acts as anti-cancer agent during $H$. pylori induced inflammation and cancer development. hCAP-18/LL-37 is constitutively secreted by surface epithelial cells and epithelial cells in the fundic glands, and its expression is enhanced in the case of $H$. pylori infection, where it exerts protective and bactericidal effects. In contrast, the level of LL-37 in various types of gastric cancers is significantly reduced (Hase et al. 2003; Wu et al. 2010b, c). This discovery was the starting point of the hypothesis that LL-37 possesses antitumor properties.

\section{LL-37-Mediated Inhibition of Proteasome Limits Gastric Cancer Development}

LL-37 in gastric cancer cells acts as cancer-suppressing agent due to its ability to inhibit the proteasome in gastric tumor tissues (Wu et al. 2010b). The proteasome is the main system linked with intracellular protein degradation and its connection with cell proliferation, apoptosis, and 
stabilization of cell cycle has made it an attractive target for cancer therapy (Krętowski et al. 2015; Richardson et al. 2005; Steg et al. 2014; Wu et al. 2010a; Yerlikaya et al. 2015). In gastric cancer cells, human cathelicidin inhibited the proteasome, promoting signaling through the bone morphogenic protein (BMP) pathway. This effect leads to increased expression of BMP4, up-regulation of cyclinedependent kinase inhibitor p21 ${ }^{\text {WafI/ClipI }}$, and down-regulation of cyclin $E_{2}$. Considering that cyclin $E_{2}$ and $\mathrm{p} 21^{\text {WafI/ }}$ ClipI are important factors in regulating the cell cycle (Bartek and Lukas 2001), alternations in their activities likely play a key role in the antitumor action of LL-37 via induction of $\mathrm{G}_{0} / \mathrm{G}_{1}$-phase cell cycle arrest. Interestingly, enlarged concentration of LL-37 is not necessary to achieve the antitumor effect in the cancer cells. It was revealed that LL-37 inhibits cells proliferation at the physiological levels (Wu et al. 2010b). In light of these and previous reports, down-regulation of LL-37 appears to be an important checkpoint in gastric cancer development.

\section{LL-37 and IG-19 Activate p44/42 MAPK and Control IL-32-Induced Inflammation}

As in the case of lung cancer, pro-tumorigenic properties of IL-32 were also confirmed for gastric cancer. In the context of this malignancy, up-regulation of IL-32 is not only associated with $H$. pylori infection, but also can be used as prognostic marker for gastric cancer patients since its expression is increased in human gastritis and gastric cancer cells, compared to normal cells (Ishigami et al. 2013; Peng et al. 2014; Sakitani et al. 2012). Recent studies revealed that LL-37 and its derivative IG-19 (amino acids rest 13-31) play an important role in controlling IL-32 $\gamma$ induced inflammation (Choi et al. 2014). Both peptides reduced the levels of IL-32, leading to reduce production of proinflammatory cytokines such as TNF- $\alpha$ or IL-6. This effect was observed both in peripheral blood-derived mononuclear cells and macrophages. Interestingly, the expression of the anti-inflammatory cytokine IL-1 receptor antagonist (IL-1RA) was not affected by either LL-37 or IG19, suggesting that LL-37 attenuates inflammation in the mucous membranes of the stomach, potentially also attenuating tumor growth within these tissues. The mechanism of this anti-inflammatory effect was associated with activation of p44/42 MAPK and the subsequent phosphorylation of MKP-1 (S359) (Choi et al. 2014). This observation is consistent with other reports that dual phosphatase MKP-1 plays a general role in reducing inflammation in gastric tissues (Korhonen and Moilanen 2014). It should be emphasized that LL-37 and IG-19 do not negatively affect the production of chemokines (chemotactic cytokines, whose major role is act as a chemoattractant to control the migration of cells), which play an important role in immune response to infection (Choi et al. 2014).

\section{LL-37 in Other Malignant Tumors}

\section{Malignant Melanoma}

LL-37 is secreted by human skin cells in increased amounts in response to the inflammation and infection, acting as a protective factor to reduce the possibility of infection and complications associated with the dysfunction of skin homeostasis (Frohm et al. 1997). On the other hand, immunohistochemical analysis of LL-37 expression in skin tumors revealed that there might be a relationship between the level of hCAP-18/LL-37 and the development of cancerous conditions in these cells. Several in vitro studies indicate that secretion of LL-37 in malignant melanoma cells is significantly increased compared to normal skin and hematological malignant cell lines, suggesting the possibility that LL-37 acts as a growth factor for skin tumor cells and enhances cancer development. However, the increased expression of LL-37 cannot be used as prognostic factor for patients diagnosed with malignant melanoma, since no difference in the expression of LL-37 between clinical subtypes of malignant melanoma was found (Kim et al. 2010). The mechanism by which the LL-37 would exhibit the pro-tumorigenic properties in malignant melanoma has not been thoroughly investigated. However, there are some reports on the basis of which we can hypothesize the possible link between up-regulated level of LL-37 and melanoma cancer cell growth. In a recent study, a specific role of TLR-4 in the process of melanoma cells growth was reported. Not only was TLR-4 secreted in considerable amounts in human melanomas, but it was shown to be important for cancer cell growth and migration (Takazawa et al. 2014). This result is consistent with previous reports about the involvement of TLR-4 in cancer development (Mai et al. 2013). Since LL-37 is one the endogenous agonists for TLRs-family, including TLR-4 (Mookherjee et al. 2006), we suspect that possible interactions between LL-37 and TLR-4 may impact neoplastic formation.

\section{Hematologic Malignancies: Lymphoma and Leukemia}

In contrast to ovarian, breast or lung cancer, where strong evidence of pro-tumorigenic effects of LL-37 was described, in hematologic malignancies, LL-37 might be considered as a therapeutic agent. For example, LL-37 activates apoptosis in a malignant human $\mathrm{T}$ cell line 
(Jurkat). This effect requires an increase of intracellular $\mathrm{Ca}^{2+}$ concentration and activation of calpains. LL-37 induces cell death in caspase-independent manner via loss mitochondrial transmembrane potential, connected to translocation of Bax to mitochondria and subsequent AIF transport to the nucleus (Mader et al. 2009). These results are particularly intriguing in light of research showing that the expression level of LL-37 in patients with leukemia is significantly reduced (An et al. 2005), which may affect not only tumor progression, but also resistance to infections in patients diagnosed with leukemia.

\section{Prostate Cancer}

Pro-tumorigenic properties of LL-37 were also described in development of prostate cancer. In both mouse models and human prostate cancer cells, the expression of LL-37 is altered (Hensel et al. 2011). The level of LL-37 is not only augmented compared with healthy cells, but are also associated on the severity of the disease and endocrine nature of the tumor. Those properties suggest that the level of this peptide may be a useful prognostic factor, since expression of LL-37 increases in parallel with the Gleason scale, classification system for prostate cancer based on an assessment of the histological structure of tumor growth. Additionally, androgen-independent cells secrete more LL37 than androgen-dependent cells, which can be useful in disease diagnosis. Finally, LL-37 enhances invasiveness of tumor cells via phosphorylated Erk1/2 and Akt signaling pathway (Hensel et al. 2011).

\section{Other Properties of LL-37 Linked with the Development of Tumors}

\section{LL-37 Affects Telomerase Activity}

LL-37 acts as an activator of apoptosis, although the exact mechanism by which LL-37 induces apoptosis is not fully understood. In addition to the cascade based on Bax and AIF described above, a recent study indicates that LL-37 is a binder of the telomeric G-quadruplex (Jana et al. 2013). G-quadruplexes are four-stranded DNA structures that inhibit telomerase activity and play a key role in the conservation of telomere length. Given that overexpression of telomerase is observed in $85-90 \%$ of human cancers, the possibility of inactivating this activity has become an extremely attractive target for novel anti-cancer treatments (Folini et al. 2009; Neidle 2010). LL-37 appears to stabilize G-quadruplexes and thereby reduces telomerase activity in cancer cells (Jana et al. 2013).

\section{LL-37 Activates IGF-1R}

Despite the knowledge of multiple signaling pathways through which the LL-37 may enhance or inhibit the development of cancer, new mechanisms of action of the LL-37 peptide are being discovered. For example, in 2012 LL-37 was found to interact with IGF-1R, one of the most widely overexpressed receptors in various types of human cancers (Girnita et al. 2012). IGF-1R appears to play a key role in the control of cell proliferation and metastasic
Fig. 4 LL-37 effect on cancer development. Green arrows indicate positive effect on cancer cells growth and red arrows indicate pro-tumorigenic properties of LL-37. $L L-37$ : cathelicidin LL-37, MSCs: mesenchymal stromal cells, $I G F-1 R$ : insulin-like growth factor 1 receptor, EGFR: epidermal growth factor receptor, FPR-1: formyl peptide receptor

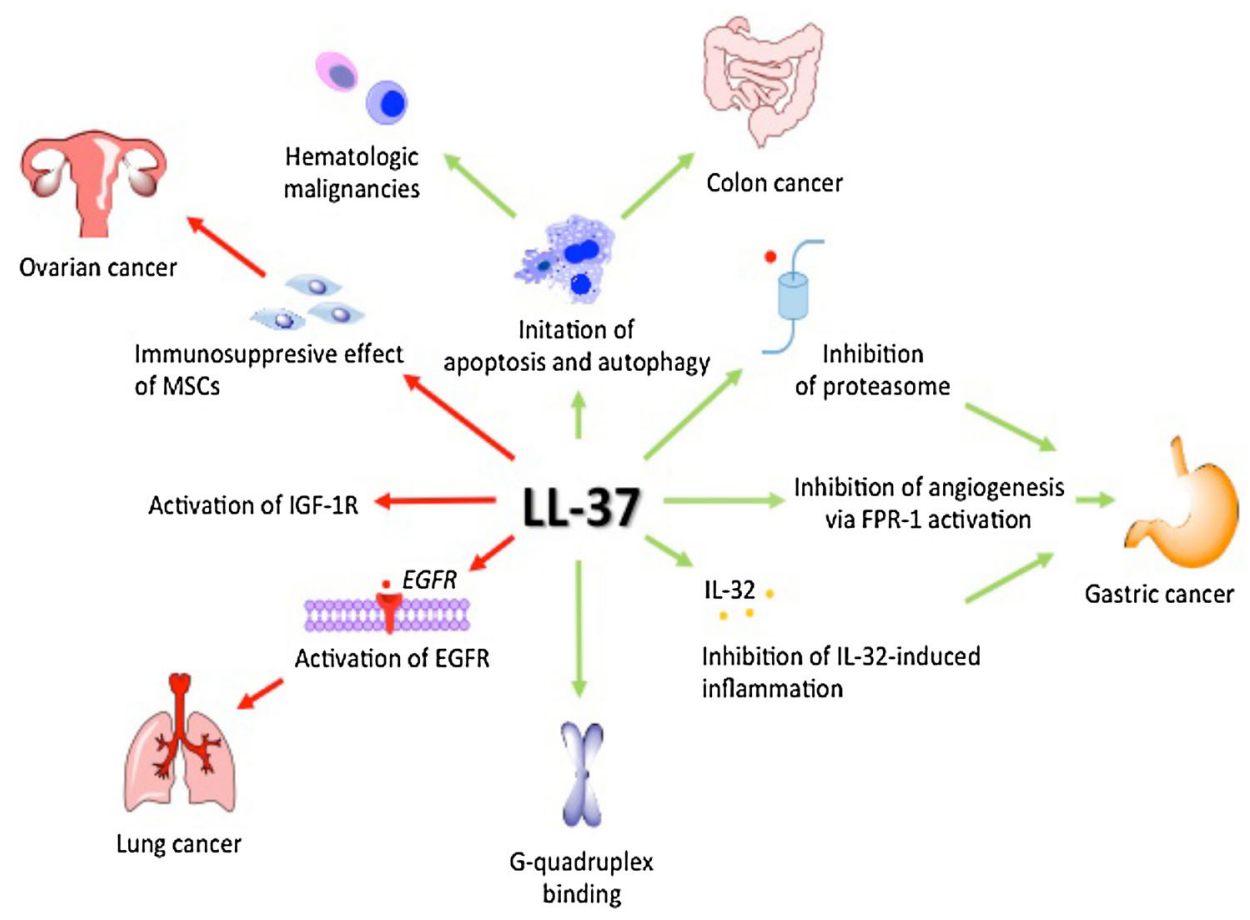


potential (Khandwala et al. 2000). Various experiments show that LL-37 might act as a partial agonist for IGF-1R, triggering $\beta$-arrestin-1-dependent activation of MAPK/ ERK, without affecting PI3K/Akt activity (Girnita et al. 2012).

\section{Conclusions}

The research results summarized above clearly indicate that the role of LL-37 in tumor development is tissuespecific (Fig. 4). Depending on tumor biology, LL-37 may act either as a pro-tumorigenic or anti-cancer agent. Moreover, a central issue is the change in the expression of LL-37 in a given tumor compared to healthy tissue of similar origin. Unfortunately, at this point it is not possible to make an indisputable judgment on the effect of LL-37 on cancer development. In 2010, the relationship of LL-37 and cancer was first reviewed (Wu et al. 2010c). Five years later, the same picture remains. Further studies on the biological activity of LL-37 are needed to ultimately define the role of this important peptide and potential therapeutic in carcinogenesis.

Open Access This article is distributed under the terms of the Creative Commons Attribution 4.0 International License (http:// creativecommons.org/licenses/by/4.0/), which permits unrestricted use, distribution, and reproduction in any medium, provided you give appropriate credit to the original author(s) and the source, provide a link to the Creative Commons license, and indicate if changes were made.

\section{References}

Agerberth B, Charo J, Werr J et al (2000) The human antimicrobial and chemotactic peptides LL-37 and alpha-defensins are expressed by specific lymphocyte and monocyte populations. Blood 96:3086-3093

Alzahrani S, Lina TT, Gonzalez J et al (2014) Effect of Helicobacter pylori on gastric epithelial cells. World J Gastroenterol 20:12767-12780

An LL, Ma XT, Yang YH et al (2005) Marked reduction of LL-37/ hCAP-18, an antimicrobial peptide, in patients with acute myeloid leukemia. Int J Hematol 81:45-47

Anand P, Kunnumakkara AB, Sundaram C et al (2008) Cancer is a preventable disease that requires major lifestyle changes. Pharm Res 25:2097-2116

Armogida SA, Yannaras NM, Melton AL et al (2004) Identification and quantification of innate immune system mediators in human breast milk. Allergy Asthma Proc 25:297-304

Arnoult D, Gaume B, Karbowski M et al (2003) Mitochondrial release of AIF and EndoG requires caspase activation downstream of Bax/Bak-mediated permeabilization. EMBO J 22:4385-4399

Bals R, Wang X, Zasloff M et al (1998) The peptide antibiotic LL-37/ hCAP-18 is expressed in epithelia of the human lung where it has broad antimicrobial activity at the airway surface. Proc Natl Acad Sci USA 95:9541-9546
Barlow PG, Svoboda P, Mackellar A et al (2011) Antiviral activity and increased host defense against influenza infection elicited by the human cathelicidin LL-37. PLoS One 6:e25333

Bartek J, Lukas J (2001) Pathways governing G1/S transition and their response to DNA damage. FEBS Lett 490:117-122

Bucki R, Janmey PA (2006) Interaction of the gelsolin-derived antibacterial PBP 10 peptide with lipid bilayers and cell membranes. Antimicrobial Agents Chemother 50:2932-2940

Bucki R, Pastore JJ, Randhawa P et al (2004) Antibacterial activities of rhodamine B-conjugated gelsolin-derived peptides compared to those of the antimicrobial peptides cathelicidin LL37, magainin II, and melittin. Antimicrobial Agents Chemother 48:1526-1533

Bucki R, Byfield FJ, Janmey PA (2007) Release of the antimicrobial peptide LL-37 from DNA/F-actin bundles in cystic fibrosis sputum. Eur Respir J 29:624-632

Bucki R, Namiot DB, Namiot Z et al (2008) Salivary mucins inhibit antibacterial activity of the cathelicidin-derived LL-37 peptide but not the cationic steroid CSA-13. J Antimicrob Chemother 62:329-335

Bucki R, Leszczynska K, Namiot A et al (2010) Cathelicidin LL-37: a multitask antimicrobial peptide. Arch Immunol Ther Exp 58:15-25

Byfield FJ, Kowalski M, Cruz K et al (2011) Cathelicidin LL-37 increases lung epithelial cell stiffness, decreases transepithelial permeability, and prevents epithelial invasion by Pseudomonas aeruginosa. J Immunol 187:6402-6409

Castells M, Milhas D, Gandy C et al (2013) Microenvironment mesenchymal cells protect ovarian cancer cell lines from apoptosis by inhibiting XIAP inactivation. Cell Death Dis 4:e887

Chen PM, Yen ML, Liu KJ et al (2011) Immunomodulatory properties of human adult and fetal multipotent mesenchymal stem cells. J Biomed Sci 18:49

Cheng M, Ho S, Yoo JH et al (2014) Cathelicidin suppresses colon cancer development by inhibition of cancer associated fibroblasts. Clin Exp Gastroenterol 8:13-29

Choi KY, Napper S, Mookherjee N (2014) Human cathelicidin LL-37 and its derivative IG-19 regulate interleukin-32-induced inflammation. Immunology 143:68-80

Chuang CM, Monie A, Wu A et al (2009) Treatment with LL-37 peptide enhances antitumor effects induced by $\mathrm{CpG}$ oligodeoxynucleotides against ovarian cancer. Hum Gene Ther 20:303-313

Clendenen TV, Lundin E, Zeleniuch-Jacquotte A et al (2011) Circulating inflammation markers and risk of epithelial ovarian cancer. Cancer Epidemiol Biomarkers Prev 20:799-810

Coffelt SB, Waterman RS, Florez L et al (2008) Ovarian cancers overexpress the antimicrobial protein hCAP-18 and its derivative LL-37 increases ovarian cancer cell proliferation and invasion. Int J Cancer 122:1030-1039

Coffelt SB, Marini FC, Watson K et al (2009) The pro-inflammatory peptide LL-37 promotes ovarian tumor progression through recruitment of multipotent mesenchymal stromal cells. Proc Natl Acad Sci USA 106:3806-3811

Cohen S, Bruchim I, Graiver D et al (2013) Platinum-resistance in ovarian cancer cells is mediated by IL- 6 secretion via the increased expression of its target cIAP-2. J Mol Med 91:357-368

Currie SM, Findlay EG, McHugh BJ et al (2013) The human cathelicidin LL-37 has antiviral activity against respiratory syncytial virus. PLoS One 8:e73659

Dinarello CA, Kim SH (2006) IL-32, a novel cytokine with a possible role in disease. Ann Rheum Dis 65(Suppl 3):iii61-iii64

Donato AL, Huang Q, Liu X et al (2014) Caspase 3 promotes surviving melanoma tumor cell growth after cytotoxic therapy. J Invest Dermatol 134:1686-1692 
Dosler S, Karaaslan E (2014) Inhibition and destruction of Pseudomonas aeruginosa biofilms by antibiotics and antimicrobial peptides. Peptides 62:32-37

Felaco P, Castellani ML, De Lutiis MA et al (2009) IL-32: a newlydiscovered proinflammatory cytokine. J Biol Regul Homeost Agents 23:141-147

Ferrari D, Pizzirani C, Adinolfi E et al (2006) The P2X7 receptor: a key player in IL-1 processing and release. J Immunol 176:3877-3883

Folini M, Gandellini P, Zaffaroni N (2009) Targeting the telosome: therapeutic implications. Biochim Biophys Acta 1792:309-316

Frohm M, Agerberth B, Ahangari G et al (1997) The expression of the gene coding for the antibacterial peptide LL-37 is induced in human keratinocytes during inflammatory disorders. J Biol Chem 272:15258-15263

Galluzzi L, Joza N, Tasdemir E et al (2008) No death without life: vital functions of apoptotic effectors. Cell Death Differ 15:1113-1123

Gao P, Zhao H, You J et al (2014) Association between interleukin-8 $-251 \mathrm{~A} / \mathrm{T}$ polymorphism and risk of lung cancer: a meta-analysis. Cancer Invest 32:518-525

Girnita A, Zheng H, Grönberg A et al (2012) Identification of the cathelicidin peptide LL-37 as agonist for the type I insulin-like growth factor receptor. Oncogene 31:352-365

Hase K, Murakami M, Iimura M et al (2003) Expression of LL-37 by human gastric epithelial cells as a potential host defense mechanism against Helicobacter pylori. Gastroenterology 125:1613-1625

Heilborn JD, Nilsson MF, Jimenez CI et al (2005) Antimicrobial protein hCAP18/LL-37 is highly expressed in breast cancer and is a putative growth factor for epithelial cells. Int $\mathrm{J}$ Cancer 114:713-719

Hensel JA, Chanda D, Kumar S et al (2011) LL-37 as a therapeutic target for late stage prostate cancer. Prostate 71:659-670

Huang Q, Li F, Liu X et al (2011) Caspase 3-mediated stimulation of tumor cell repopulation during cancer radiotherapy. Nat Med 17:860-866

Hurtado P, Peh CA (2010) LL-37 promotes rapid sensing of CpG oligodeoxynucleotides by $\mathrm{B}$ lymphocytes and plasmacytoid dendritic cells. J Immunol 184:1425-1435

Ishigami S, Arigami T, Uchikado Y et al (2013) IL-32 expression is an independent prognostic marker for gastric cancer. Med Oncol 30:472

Jana J, Kar RK, Ghosh A et al (2013) Human cathelicidin peptide LL37 binds telomeric G-quadruplex. Mol BioSyst 9:1833-1836

Joosten LA, Netea MG, Kim SH et al (2006) IL-32, a proinflammatory cytokine in rheumatoid arthritis. Proc Natl Acad Sci USA 103:3298-3303

Khandwala HM, McCutcheon IE, Flyvbjerg A et al (2000) The effects of insulin-like growth factors on tumorigenesis and neoplastic growth. Endocr Rev 21:215-244

Kim JE, Kim HJ, Choi JM et al (2010) The antimicrobial peptide human cationic antimicrobial protein-18/cathelicidin LL-37 as a putative growth factor for malignant melanoma. Br J Dermatol 163:959-967

Kim HJ, Hwang SW, Kim N et al (2014) Helicobacter pylori and molecular markers as prognostic indicators for gastric cancer in Korea. J Cancer Prev 19:56-67

Koczulla R, von Degenfeld G, Kupatt C et al (2003) An angiogenic role for the human peptide antibiotic LL-37/hCAP-18. J Clin Invest 111:1665-1672

Koensgen D, Bruennert D, Ungureanu S et al (2015) Polymorphism of the IL-8 gene and the risk of ovarian cancer. Cytokine 71:334-338
Korhonen R, Moilanen E (2014) Mitogen-activated protein kinase phosphatase 1 as an inflammatory factor and drug target. Basic Clin Pharmacol Toxicol 114:24-36

Krętowski R, Stypułkowska A, Cechowska-Pasko M (2015) Efficient apoptosis and necrosis induction by proteasome inhibitor: bortezomib in the DLD-1 human colon cancer cell line. Mol Cell Biochem 398:165-173

Kuroda K, Fukuda T, Yoneyama H et al (2012) Anti-proliferative effect of an analogue of the LL-37 peptide in the colon cancer derived cell line HCT116 $\mathrm{p}^{+/+}$and $\mathrm{p} 53^{-/-}$. Oncol Rep 28:829-834

Kuroda K, Fukuda T, Okumura K et al (2013) Ceragenin CSA-13 induces cell cycle arrest and antiproliferative effects in wild-type and p53 null mutant HCT116 colon cancer cells. Anticancer Drugs 24:826-834

Lee S, Kim JH, Kim H et al (2011) Activation of the interleukin-32 pro-inflammatory pathway in response to human papillomavirus infection and over-expression of interleukin-32 controls the expression of the human papillomavirus oncogene. Immunology 132:410-420

Leszczynska K, Namiot D, Byfield FJ et al (2013) Antibacterial activity of the human host defence peptide LL-37 and selected synthetic cationic lipids against bacteria associated with oral and upper respiratory tract infections. J Antimicrob Chemother 68:610-618

Levine B, Abrams J (2008) p53: the Janus of autophagy? Nat Cell Biol 10:637-639

Li X, Li Y, Han H et al (2006) Solution structures of human LL-37 fragments and NMR-based identification of a minimal membrane-targeting antimicrobial and anticancer region. J Am Chem Soc 128:5776-5785

Lim R, Lappas M, Riley C et al (2013) Investigation of human cationic antimicrobial protein-18 (hCAP-18), lactoferrin and CD163 as potential biomarkers for ovarian cancer. J Ovarian Res 6:5

López-García B, Lee PH, Yamasaki K et al (2005) Anti-fungal activity of cathelicidins and their potential role in Candida albicans skin infection. J Invest Dermatol 125:108-115

Macciò A, Madeddu C (2012) Inflammation and ovarian cancer. Cytokine 58:133-147

Mader JS, Mookherjee N, Hancock RE et al (2009) The human host defense peptide LL-37 induces apoptosis in a calpain- and apoptosis-inducing factor-dependent manner involving Bax activity. Mol Cancer Res 7:689-702

Mai CW, Kang YB, Pichika MR (2013) Should a Toll-like receptor 4 (TLR-4) agonist or antagonist be designed to treat cancer? TLR4: its expression and effects in the ten most common cancers. Onco Targets Ther 6:1573-1587

McSorley MA, Alberg AJ, Allen DS et al (2007) C-reactive protein concentrations and subsequent ovarian cancer risk. Obstet Gynecol 109:933-941

Mishra J, Drummond J, Quazi SH et al (2013) Prospective of colon cancer treatments and scope for combinatorial approach to enhanced cancer cell apoptosis. Crit Rev Oncol Hematol $86: 232-250$

Montreekachon P, Chotjumlong P, Bolscher JG et al (2011) Involvement of $\mathrm{P} 2 \mathrm{X}(7)$ purinergic receptor and MEK1/2 in interleukin- 8 up-regulation by LL-37 in human gingival fibroblasts. J Periodontal Res 46:327-337

Mookherjee N, Brown KL, Bowdish DM et al (2006) Modulation of the TLR-mediated inflammatory response by the endogenous human host defense peptide LL-37. J Immunol 176:2455-2464

Muccioli M, Benencia F (2014) Toll-like Receptors in ovarian cancer as targets for immunotherapies. Front Immunol 5:341 
Neidle S (2010) Human telomeric G-quadruplex: the current status of telomeric G-quadruplexes as therapeutic targets in human cancer. FEBS J 277:1118-1125

Netea MG, Azam T, Lewis EC et al (2006) Mycobacterium tuberculosis induces interleukin-32 production through a caspase-1/IL-18/interferon-gamma-dependent mechanism. PLoS Med 3:e277

Niemirowicz K, Prokop I, Wilczewska AZ et al (2015) Magnetic nanoparticles enhance the anticancer activity of cathelicidin LL37 peptide against colon cancer cells. Int $\mathrm{J}$ Nanomedicine 10:3843-3853

Nold-Petry CA, Rudloff I, Baumer Y et al (2014) IL-32 promotes angiogenesis. J Immunol 192:589-602

Ostrand-Rosenberg S (2008) Immune surveillance: a balance between protumor and antitumor immunity. Curr Opin Genet Dev $18: 11-18$

Ouyang L, Shi Z, Zhao S et al (2012) Programmed cell death pathways in cancer: a review of apoptosis, autophagy and programmed necrosis. Cell Prolif 45:487-498

Overhage J, Campisano A, Bains M et al (2008) Human host defense peptide LL-37 prevents bacterial biofilm formation. Infect Immun 76:4176-4182

Peng LS, Zhuang Y, Li WH et al (2014) Elevated interleukin-32 expression is associated with Helicobacter pylori-related gastritis. PLoS One 9:e88270

Prevete N, Liotti F, Visciano C et al (2015) The formyl peptide receptor 1 exerts a tumor suppressor function in human gastric cancer by inhibiting angiogenesis. Oncogene 34:3826-3838

Ren SX, Cheng AS, To KF et al (2012) Host immune defense peptide LL-37 activates caspase-independent apoptosis and suppresses colon cancer. Cancer Res 72:6512-6523

Ren SX, Shen J, Cheng AS et al (2013) FK-16 derived from the anticancer peptide LL-37 induces caspase-independent apoptosis and autophagic cell death in colon cancer cells. PLoS One 8:e63641

Richardson PG, Mitsiades C, Hideshima T et al (2005) Proteasome inhibition in the treatment of cancer. Cell Cycle 4:290-296

Rico-Mata R, De Leon-Rodriguez LM, Avila EE (2013) Effect of antimicrobial peptides derived from human cathelicidin LL-37 on Entamoeba histolytica trophozoites. Exp Parasitol 133:300-306

Romero I, Bast RC (2012) Minireview: human ovarian cancer: biology, current management, and paths to personalizing therapy. Endocrinology 153:1593-1602

Sakitani K, Hirata Y, Hayakawa Y et al (2012) Role of interleukin-32 in Helicobacter pylori-induced gastric inflammation. Infect Immun 80:3795-3803

Scott MG, Davidson DJ, Gold MR et al (2002) The human antimicrobial peptide LL-37 is a multifunctional modulator of innate immune responses. J Immunol 169:3883-3891

Shaykhiev R, Beisswenger C, Kändler K et al (2005) Human endogenous antibiotic LL-37 stimulates airway epithelial cell proliferation and wound closure. Am J Physiol Lung Cell Mol Physiol 289:L842-L848

Shioya M, Nishida A, Yagi Y et al (2007) Epithelial overexpression of interleukin-32alpha in inflammatory bowel disease. Clin Exp Immunol 149:480-486

Sieprawska-Lupa M, Mydel P, Krawczyk K et al (2004) Degradation of human antimicrobial peptide LL-37 by Staphylococcus aureus-derived proteinases. Antimicrob Agents Chemother 48:4673-4679

Simonsen DF, Farkas DK, Søgaard M et al (2014) Tuberculosis and risk of cancer: a Danish nationwide cohort study. Int J Tuberc Lung Dis 18:1211-1219
Sørensen OE, Follin P, Johnsen AH et al (2001) Human cathelicidin, hCAP-18, is processed to the antimicrobial peptide LL37 by extracellular cleavage with proteinase 3. Blood 97:3951-3959

Sorrentino C, Di Carlo E (2009) Expression of IL-32 in human lung cancer is related to the histotype and metastatic phenotype. Am J Respir Crit Care Med 180:769-779

Steg AD, Burke MR, Amm HM et al (2014) Proteasome inhibition reverses hedgehog inhibitor and taxane resistance in ovarian cancer. Oncotarget 5:7065-7080

Takazawa Y, Kiniwa Y, Ogawa E et al (2014) Toll-like receptor 4 signaling promotes the migration of human melanoma cells. Tohoku J Exp Med 234:57-65

Tjabringa GS, Aarbiou J, Ninaber DK et al (2003) The antimicrobial peptide LL-37 activates innate immunity at the airway epithelial surface by transactivation of the epidermal growth factor receptor. J Immunol 171:6690-6696

Touboul C, Vidal F, Pasquier J et al (2014) Role of mesenchymal cells in the natural history of ovarian cancer: a review. J Transl Med 12:271

Travis SM, Anderson NN, Forsyth WR et al (2000) Bactericidal activity of mammalian cathelicidin-derived peptides. Infect Immun 68:2748-2755

Van Cutsem E, Geboes K (2007) The multidisciplinary management of gastrointestinal cancer. The integration of cytotoxics and biologicals in the treatment of metastatic colorectal cancer. Best Pract Res Clin Gastroenterol 21:1089-1108

Vandamme D, Landuyt B, Luyten W et al (2012) A comprehensive summary of LL-37, the factotum human cathelicidin peptide. Cell Immunol 280:22-35

von Haussen Koczulla R, Shaykhiev RJ et al (2008) The host defence peptide LL-37/hCAP-18 is a growth factor for lung cancer cells. Lung Cancer 59:12-23

Wang G (2014) Human antimicrobial peptides and proteins. Pharmaceuticals 7:545-594

Weber G, Chamorro CI, Granath F et al (2009) Human antimicrobial protein hCAP18/LL-37 promotes a metastatic phenotype in breast cancer. Breast Cancer Res 11:R6

$\mathrm{Wu}$ WK, Cho $\mathrm{CH}$, Lee CW et al (2010a) Proteasome inhibition: a new therapeutic strategy to cancer treatment. Cancer Lett 293:15-22

Wu WK, Sung JJ, To KF et al (2010b) The host defense peptide LL37 activates the tumor-suppressing bone morphogenetic protein signaling via inhibition of proteasome in gastric cancer cells. J Cell Physiol 223:178-186

Wu WK, Wang G, Coffelt SB et al (2010c) Emerging roles of the host defense peptide LL-37 in human cancer and its potential therapeutic applications. J Int Cancer 127:1741-1747

Wu WK, Coffelt SB, Cho CH et al (2012) The autophagic paradox in cancer therapy. Oncogene 31:939-953

Yang De, Chen Q, Schmidt AP et al (2000) LL-37, the neutrophil granule- and epithelial cell-derived cathelicidin, utilizes formyl peptide receptor-like 1 (FPRL1) as a receptor to chemoattract human peripheral blood neutrophils, monocytes, and $\mathrm{T}$ cells. J Exp Med 192:1069-1074

Yerlikaya A, Okur E, Baykal AT et al (2015) A proteomic analysis of p53-independent induction of apoptosis by bortezomib in 4T1 breast cancer cell line. J Proteomics 113:315-325

Yousif NG, Al-Amran FG, Hadi N et al (2013) Expression of IL-32 modulates NF- $\kappa$ B and p38 MAP kinase pathways in human esophageal cancer. Cytokine 61:223-227

Zaiou M, Gallo RL (2002) Cathelicidins, essential gene-encoded mammalian antibiotics. J Mol Med 80:549-561 
Zeng X, Yan T, Schupp JE et al (2007) DNA mismatch repair initiates 6-thioguanine-induced autophagy through p53 activation in human tumor cells. Clin Cancer Res 13:1315-1321

Zeng Q, Li S, Zhou Y et al (2014) Interleukin-32 contributes to invasion and metastasis of primary lung adenocarcinoma via NF-
kappaB induced matrix metalloproteinases 2 and 9 expression. Cytokine 65:24-32 